\title{
FABRICIO LOPEZ
}

A cidade de Santos não é apenas o local que Fabricio Lopez escolheu para instalar seu ateliê. Nascido na baixada santista, o artista chegou a viver durante 12 anos em São Paulo, onde cursou artes plásticas, mas desde 2009 voltou para sua cidade de origem, onde mora e trabalha. O retorno a Santos evidencia a importância que esse lugar desempenha na obra de Fabricio e a relação íntima que ele mantém com esse espaço, algo que fica claro em diversos momentos da conversa com o artista, como quando ele explica sobre a origem das imagens que utiliza em sua produção ou ainda quando propõe um passeio pelo centro velho da cidade para mostrar seus diversos pontos históricos.

A primeira e mais evidente influência do local na obra de Fabricio notase justamente nas imagens que o artista grava nos grandes compensados de madeira que preechem uma sala inteira do Centro Universitário Maria Antonia na exposição A concha eloquente do coração. Nessa série de matrizes de xilogravuras, muitas das imagens remetem à experiência visual propiciada pela vivência do ambiente - ao mesmo tempo urbano e natural - da cidade de Santos. Uma das matrizes, por exemplo, retrata o interior de um casarão antigo e teve como fonte a casa vizinha ao ateliê do artista, no bairro do Valongo. Fabricio conta que, antes mesmo de se mudar de volta para Santos, já tinha comprado um caiaque: "Minha filha dormia, eu botava meu caiaque no carro, chegava na praia e remava da meia noite à uma da manhã. Essa experiência visual tinha enfrentamento com a natureza e com o mar". Outra fonte para as imagens retratadas em sua obra, igualmente pessoal e cotidiana, é o âmbito familiar do artista, que diz: "As xilogravuras das borboletas e do tórax têm a ver com meus filhos, eu trazia imagens de xerox e fazia projeções de insetos grandes nas paredes com eles em casa". 


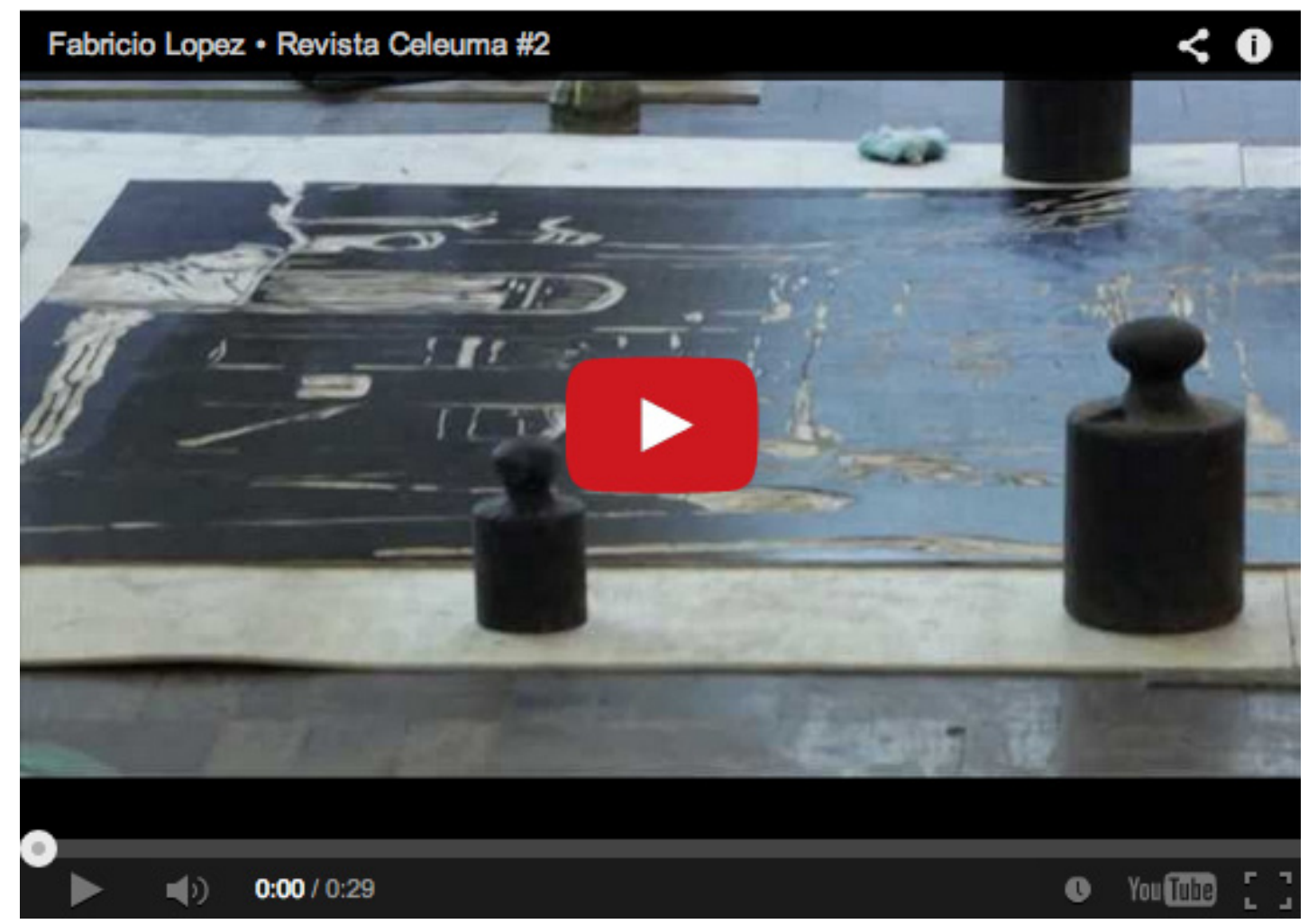

O trabalho de Fabricio também esbarra em outras vivências: o artista trabalha com arte educação e já integrou, junto a outros jovens artistas, alguns ateliês coletivos, como o Espaço Coringa e a Associação Cultural Jatobá, AJA, em São Paulo. Além de ampliar o diálogo com a produção de outros criadores, Fabricio identifica nessa experiência uma oportunidade de pensar seu próprio trabalho: "A vivência coletiva foi algo que me deu muito respaldo para a produção individual. O Ernesto [Ernesto Bonato, xilogravurista] faz uma analogia bonita: Diz que mesmo na coletividade, onde todos os pescadores estão juntos, é possível dar um mergulho e alcançar, com o seu fôlego, algo que é só seu”. Além disso, Fabrício já trabalhou pintura, desenho e até cenografia em teatro e TV; mas foi com a xilogravura que seu trabalho adquiriu grandes dimensões, tanto em notoriedade quanto, propriamente, no tamanho. A maioria das xilogravuras de Fabrício ultrapassa um metro e meio de altura e necessitam de um longo processo para serem realizadas. Ele conta que, dependendo do desenho, uma xilo pode demorar até um ano e meio para ser concluída, atividade que demanda, além de tempo, esforço físico, já que o artista trabalha agachado, gravando, no chão, a placa de 
madeira.

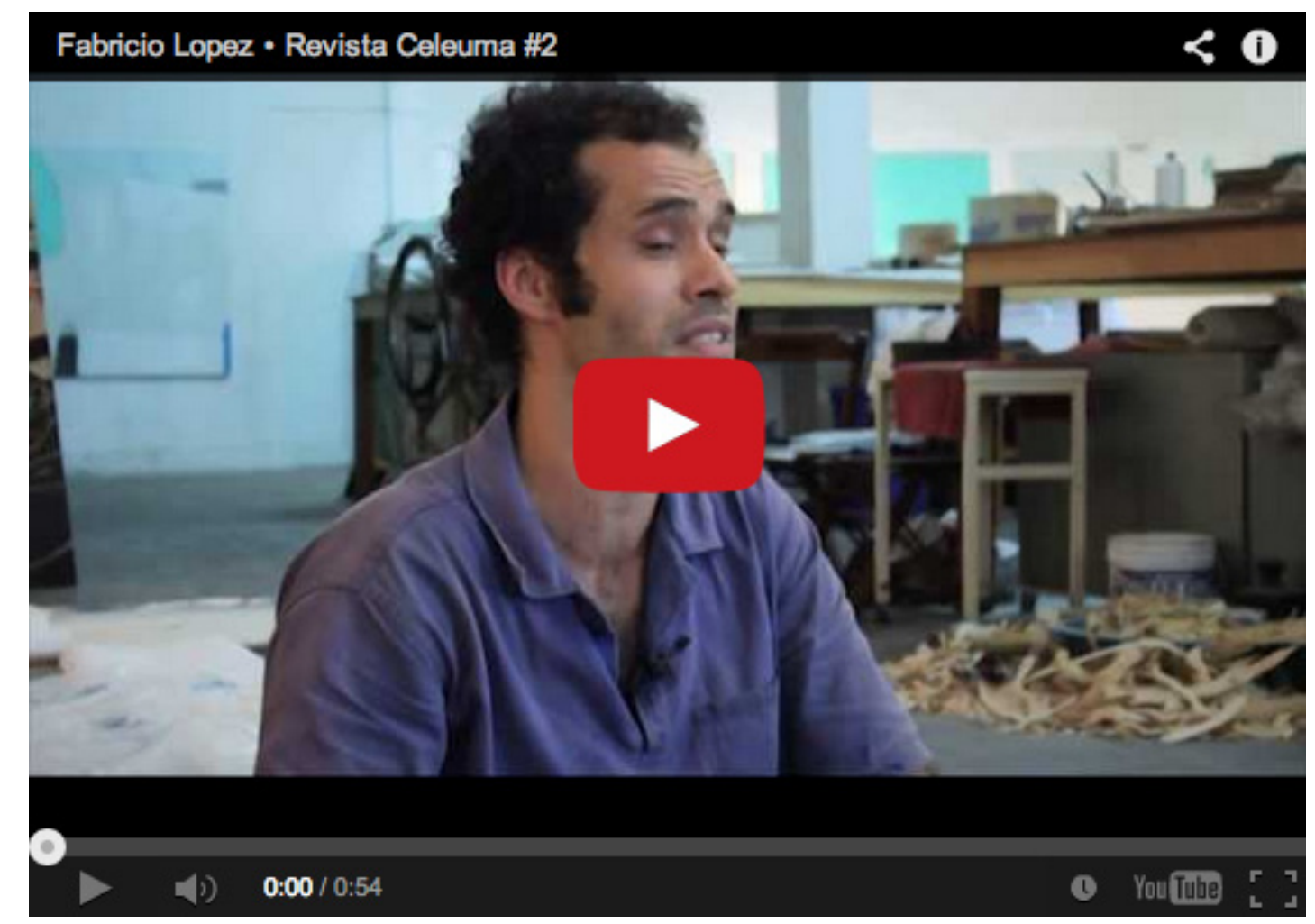

Mas esforço físico não é a única exigência do trabalho de Fabricio Lopez. Por trabalhar com grandes chapas de madeira, o artista sentiu a necessidade de adaptar os materiais utilizados na produção das xilogravuras. Assim, goivas, facas e formões passaram a ter, já há alguns anos, o tamanho e o corte adequados para o tipo de gravação realizado pelo artista. A impressão das imagens também se torna algo mais complicado quando são desenvolvidas as matrizes. As grandes imagens gravadas são impressas, por meio de um processo manual e preciso, em folhas inteiriças, que posteriormente podem ser divididas em pedaços menores, o que facilita o transporte das obras.

Apesar de o trabalho com xilogravura demandar grande esforço manual, ele exige, também, certa delicadeza, já que o "instrumento de corte é o instrumento de registro", por isso qualquer erro durante o processo pode comprometer o resultado final. Mas essa imprevisibilidade é uma 
questão que, de certo modo, agrada Fabricio, já que ele nem sempre desenha ou marca a placa antes de começar a gravação. O início pode acontecer de modo intuitivo, com a madeira sendo gravada a esmo, o que torna o trabalho mais difícil e, de certo modo, exige maior domínio técnico, afinal, como lembra o artista já no fim da conversa, "qualquer local que você cave, emite luz".

por Thierry Freitas e Lara Rivetti.

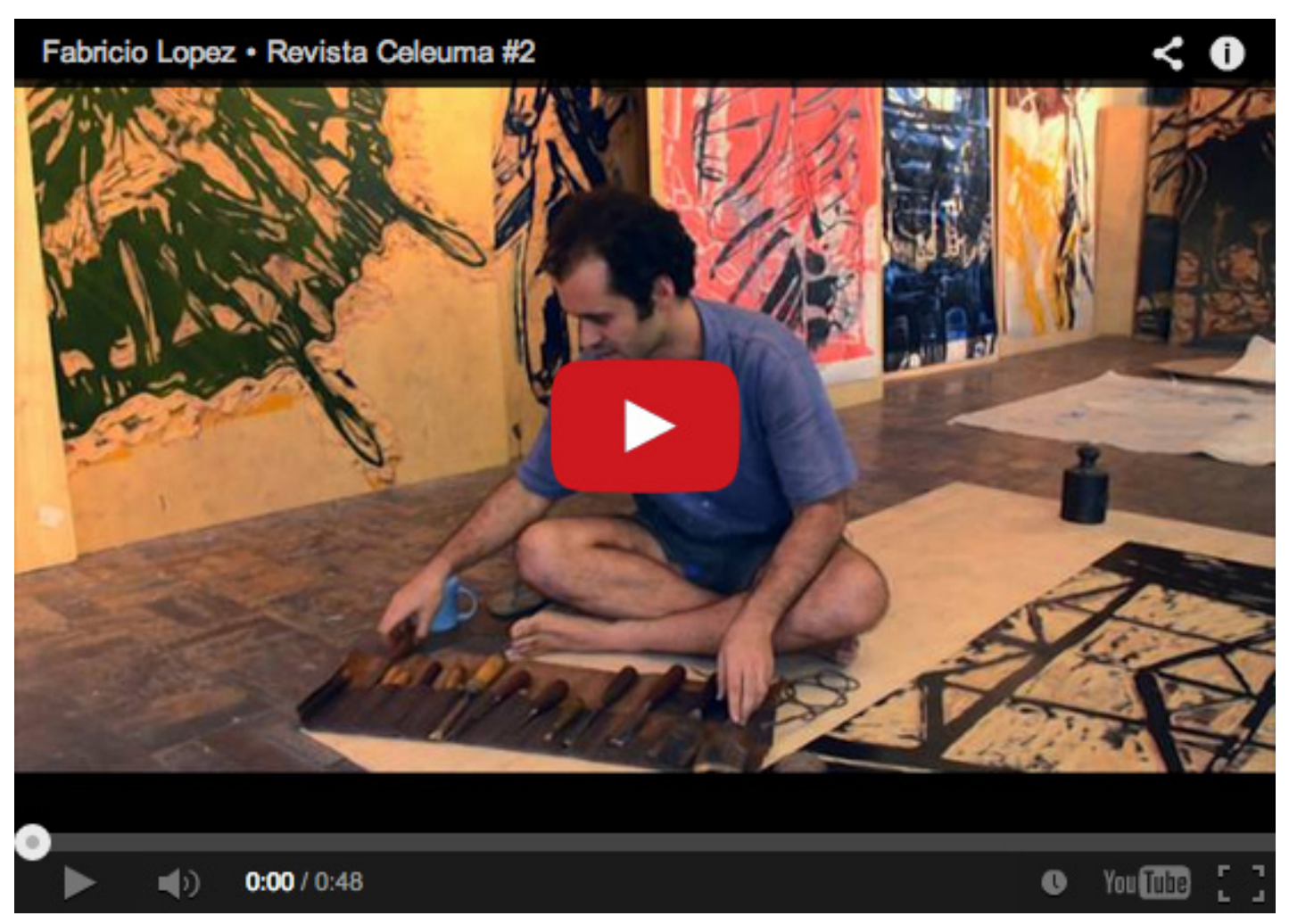

